\title{
Research agencies prepare to tighten budget belts
}

MAJOR cuts in the US science budget which could virtually eliminate any real growth in research funding over the next eighteen months are expected to result from President Carter's moves to reduce federal spending in an effort to lower the rate of inflation.

No cuts have yet been officially decided. But the President is expected to make public within the near future how he intends to move towards a balanced budget by eliminating about $\$ 4$ billion of federal expenditure in the current fiscal year by cutting back on commitments already made, and $\$ 15$ billion in the 1981 fiscal year which begins on 1 October by reducing the budget request to Congress.

Virtually the only area expected to emerge unscathed is the defence budget. And since the science budget is an area of discretionary expenditure - unlike social security, for example, where expenditure is mandated by law - it can expect to shoulder a fair part of the burden.

Research agency heads were asked last week by the Office of Management and Budget (OMB) how they would meet given targets for reducing expenditure. Among the cuts under discussion are thought to be: - National Institutes of Health: OMB has asked for cuts of $\$ 170$ million in the rest of the 1980 budget, and $\$ 340$ million (about $10 \%$ of the total) in the 1981 budget as part of a $\$ 700$ million reduction for the Department of Health, Education and Welfare.

One immediate casualty could be the administration's attempt to maintain the number of new competitive research grants at about 5000 . This may be reduced to about 3,500 , considerably raising the necessary quality of applications likely to be funded. There would also be a general cutback across the whole range of NIH's research activities, possibly resulting in the loss of some scientists' jobs.

- National Aeronautics and Space Administration: OMB is said to have asked NASA to prepare for cuts of $\$ 760$ million, a sum equivalent to $14 \%$ of the civilian space budget. This would affect almost all of the NASA's programmes, in particular the launch of the space shuttle.

Various planetary missions, such as the Galileo launch to Jupiter, and the solarpolar mission to be carried out jointly with the European Space Agency, would have to be put back, and perhaps even eliminated. The gamma ray observatory, recommended as a new start for 1981, may also be affected.

- National Science Foundation: cuts in the order of $\$ 90$ million to $\$ 100$ million about $9 \%$ of the proposed 1981 budget are under discussion with OMB. The budget office has suggested that where possible basic research expenditures should be protected. The main impact is therefore likely to fall on areas such as applied science and science education

- Department of Energy: several largescale energy research projects have to be abandoned or cut back. Among those being closely studied last week in solar energy, for example, were the "power tower" under construction at Barstow in California, and the Ocean Thermal Test Facility (OTEC), now nearing completion off Hawaii.

- National Bureau of Standards: OMB has asked for cuts of about $\$ 7$ million, and bureau officials have indicated that at the top of their list is likely to be a new $\$ 5$ million initiative to enhance basic research in the agency, a package of eight proposals included in the original 1981 budget request with the specific endorsement of the Office of Science and Technology Policy.

Administration officials stressed last week that most of the potential cuts were still under negotiation. But President Carter warned state and city officials visiting the White House to expect some unpleasant surprises in the near future -and discussions were taking place last weekend to put together the final package.

If the cuts are made as expected, then they are unlikely to be strongly resisted by Congress, particularly in an election year when many voters will be looking for signs of financial stringency, and to oppose the cuts would be to oppose the President's anti-inflation strategy.

David Dickson

\section{Environment}

\section{IMAGE \\ UNAVAILABLE FOR COPYRIGHT REASONS}

\section{World Conservation Strategy sets priorities for global resources}

THE latest international environmental initiative was launched simultaneously last week in 32 countries, amid hopes that the time is ripe to stop squandering the Earth's natural resources. In producing its World Conservation Strategy*, the International Union for the Conservation of Nature (under the auspices of the United Nations Environment Programme and the World Wildlife Fund) has brought together a wide range of expertise to set out priorities for action to conserve and replenish global resources, from microbial cultures to tropical forests. The heaviest burden of such action would inevitably fall on developing nations, whose will may be impeccable, but whose means may be totally inadequate as the sponsors are bound to admit when they urge policy

* Avalabie trom the $M$ orid $M$ ildlite I und. 29 ( resille street. World, Kogan Page, 22.95 naperback, 25.95 hardbach. makers to take up the strategy.

The major theme of the strategy - that conservation and development must go hand-in-hand has been gathering strength since the UN Conference on the Human Environment in June, 1972. Now the call is for governments and international agencies to base their development programmes on sustainable use of species and ecosystems, which means spending the interest while keeping the capital. The authors of the strategy cite familiar worldwide evidence that much of that capital is being dissipated. Many losses are due to overfishing in the oceans, overgrazing on the land, clearing of forests and destruction of wild animals and plants, often because people are too poor to replenish their resources, even if they take a long term view.

The way to reverse the trend is not by piece meal attempts to save resources once 
they are threatened with destruction. According to the strategy, governments should consider the needs of conservation at all stages of development. As an example, the authors recommend that forestry should not be directed only towards increasing the yield of products and the provision of services such as recreation and education. Forest management must ensure that yields are sustainable, and genetic diversity is preserved. The preservation of genetic diversity in general is an immediate task for governments in order to prevent the extinction of further species of wildlife, crop plants and livestock, any of which could be needed in the future (for example, in agricultural breeding programmes or the production of drugs). The recommended approach is to preserve ecosystems intact within reserves, augmented by collections both of whole organisms, as in zoos and botanic gardens, and of genetic material such as seed and semen.

The preservation of genetic resources is also a priority for action by international agencies, which are called upon to provide a wide range of assistance such as that provided for crop plants by the International Board for Plant Genetic Resources. According to the strategy, financial assistance should also be sought from commercial enterprises that benefit from the exploitation of living resources.

Another international priority is action to halt the depletion of shared resources in oceans and river basins. The scale of losses also makes tropical forests and drylands a priority for international action. In the latter case, low rainfall, high rates of evaporation and inefficient use are encouraging the rapid spread of deserts. The strategy calls for the implementation of the wide ranging plan of action formulated at the UN Conference on Desertification in September, 1977.

The hazards that beset a scheme for environmental action, were well expressed by Mr Michael Heseltine, UK Secretary of State for the Environment, when he said at the launching ceremony in London:

"The basis of my approach - and indeed of the present government - rests on conservation, good husbandry and wise use of resources. But it would be less than frank of me to assert tht all decisions of government flow naturally and easily from that premise".

It is, he pointed out, almost always a matter of balancing a developmental need, often with a clear economic advantage, against a potential conservation loss. $\mathrm{Mr}$ Heseltine injected a further note of caution when Mr David Attenborough, naturalist and broadcaster, insisted that the people at large should compel governments everywhere to recognise the strategy, which must become a political issue. Otherwise, Attenborough said, it was doomed to be "just another abandoned lofty plan". He has set his fellow citizens a difficult task.

Mary Lindley

United Kingdom

\section{Fast reactor fuel cycle to begin}

THE United Kingdom Atomic Energy Authority has been given approval to make regular shipments of plutonium nitrate in water solution from Dounreay on the north coast of Scotland to Windscale in Cumbria, north-west England, as part of an experimental fast reactor fuel cycle. The nitrate will be the result of reprocessing of fuel elements from the Dounreay prototype fast reactor (PFR). For economic reasons the Authority plans to refabricate new fuel, perhaps by the 'sol gel' process, at Windscale rather than at Dounreay. Shipments will begin later this year, at the rate of one every two to four weeks.

Behind the decision may lie uncertainty about the future siting of the commercial demonstration fast reactor (CDFR) that the Authority would like to build. The government has promised a public enquiry on the fast breeder before any commitment is made to the CDFR, and only if it were to be built at Dounreay would it be economic to build a fuel fabrication plant there.

The shipments ultimately will be on a large scale, involving some $800 \mathrm{~kg}$ of

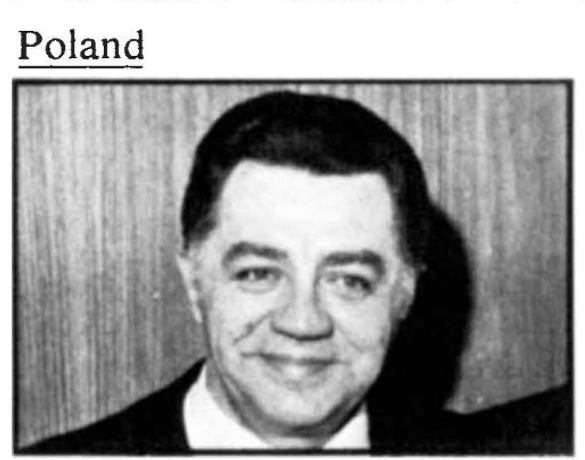

Bartosiewicz: power cooperation

\section{Energy agreement}

Mr Zbigniew Bartosiewicz, Polish Minister of Power and Atomic Energy has signed a cooperation agreement with Sir Francis Tombs, Chairman of The UK Electricity Council. The agreement covers the exchange of information and possible joint research on the more efficient use of conventional energy sources for power generation.

The Minister's five-day visit to the UK comes at a time when Poland's industrial expansion programme has outstripped generating capacity.

During his visit, Bartosiewicz attended a seminar organised by the Department of Industry, at which one of the major topics discussed was "down time" - the unscheduled stoppage of generating sets for maintenance work. UK participants in the seminar later reported that they felt the optimisation of maintenance logistics could well be a fruitful theme for cooperation. plutonium a year. Each load, carried in a specially designed 250 litre flask in a $27 \mathrm{~m}^{3}$ containment vessel, may amount to a critical mass of the metal - so the flask has had to be designed to minimise risk of criticality.

Another design problem has been the continuous radiolysis of water by alpha emission from the plutonium. This results in a build up of hydrogen and oxygen gas, in explosive proportions. An inert gas atmosphere is introduced to dilute the gas, and so reduce the risk of explosion.

"Nevertheless", says a Department of Energy note on the shipments, "assessments have been made of the possible consequences of gas ignition within the package".

The package is unlikely to be damaged in a transport accident sufficiently to breach the inner vessel, says the note. "However, if the vessel was ruptured, and in the further unlikely event that a source of ignition was present, and that the mixture of hydrogen and oxygen was in the explosive range, any resultant explosion internal or external to the containment vessel but inside the outer package would generate insufficient pressure to rupture the external structure."

The inner vessel is designed to withstand the pressure that, it is calculated, will build up in the vessel up to 250 days; then it is unlikely to rupture. The danger here is of a shipwreck, followed by a delay in recovery. The Authority has performed recovery tests on a dummy container hidden in a wreck off West Scotland, which "was found and retrieved in hours". However, tests have not been made on the time for which a damaged inner container (after a collision, say) would withstand pressure build-up.

In an impact test, however, there was cracking of the outer vessel and fracturing of the radiation shield. According to a report prepared by the Nuclear Installation Inspectorate, published last week "it can be argued that would give enhanced access to heat flux" in the case of an impact followed by fire. Although, said an Authority spokesman, "that was one we were a bit bothered about", the NII concluded that thermal tests that had been conducted (on an undamaged third-scale model) were "an adequate demonstration" of safety.

The greatest dangers may occur during the loading and unloading of the inner vessel to and from its impact-resistant container, where the Authority has assumed that the vessel would not survive a two-foot drop. But, says the Department of Energy, the Health and Safety Executive are satisfied, as a result of tests, that the vessel would survive such an impact.

Robert Waigate 